\title{
Commentary: The Norwood operation: Can we modify the nonmodifiable?
}

\author{
Edward L. Bove, MD
}

\author{
From the Department of Cardiac Surgery, University of Michigan Medical School, Ann Arbor, Mich. \\ Disclosures: Author has nothing to disclose with regard to commercial support. \\ Received for publication Jan 3, 2019; accepted for publication Jan 3, 2019; available ahead of print Feb 22, 2019. \\ Address for reprints: Edward L. Bove, MD, 1500 E Medical Center Dr, 5144 CVC, Ann Arbor, MI 48109 (E-mail: \\ elbove@umich.edu). \\ J Thorac Cardiovasc Surg 2019;158:232-3 \\ $0022-5223 / \$ 36.00$ \\ Copyright (c) 2019 by The American Association for Thoracic Surgery \\ https://doi.org/10.1016/j.jtcvs.2019.01.010
}

This is an important article reviewing 30 years of experience with the Norwood procedure at a center with largest experience reported to date. ${ }^{1}$ The large number of patients operated at a single institution with (essentially) a uniform approach makes this a valuable contribution to our literature. The study's principle finding is that although hospital survival improved in their contemporary patient cohort it has essentially plateaued, a finding that the authors attribute to the high incidence of nonmodifiable patient-specific risk factors. Other interesting findings include no difference in mortality associated with ascending aortic size and HLHS anatomic subtype (mitral and/or aortic atresia vs hypoplasia). This reviewer, coming from a center with another large experience with this procedure ( $>1300$ cases), found the results reported by the investigators very consistent with our experience. $^{2}$

Despite the value of this report, the article lacks information that would have proved to be very useful to the reader. The authors imply throughout the report that the Norwood operation, as used in this review, is used for HLHS and yet they include what are referred to as "HLHS variants" such as double inlet left ventricle and tricuspid atresia with transposition of the great arteries. Although these conditions are often treated with a Norwood operation, they represent a different group of patients with a systemic left (vs right) ventricle. Despite this concern, no mention is made if the results for these patients differ from those with classic HLHS. ${ }^{3}$ Additional valuable knowledge that might have been gained from this review include the effect of shunt type and size, interstage mortality, and individual surgeon outcomes. ${ }^{4}$

These comments should in no way detract from what is a valuable addition to the literature, one that suggests that further improvements in outcomes for the Norwood procedure have plateaued because of nonmodifiable conditions. Indeed, our own experience suggests that improved prenatal diagnosis and recommended delivery at a major cardiac center might have actually resulted in worse outcomes. This seemingly paradoxical finding is likely because patients who would not have survived hospital transfer or would not have been offered staged palliation because of

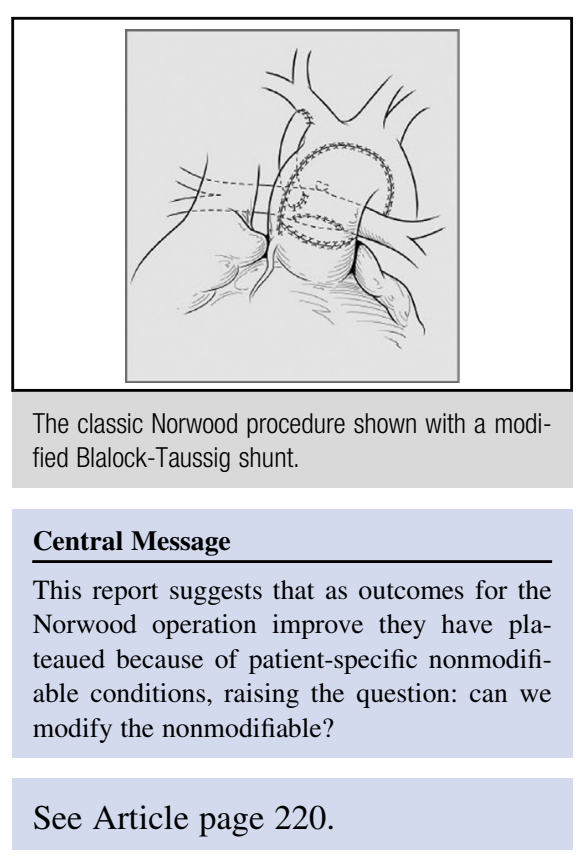

associated risk factors such as intact atrial septum, poor right ventricular function and tricuspid regurgitation, significant prematurity and/or low birth weight, and major associated congenital anomalies, now undergo a Norwood operation. Additionally, newer treatment options such as in utero intervention, hybrid procedures, and shunt type have as of yet failed to convincingly show improved overall outcomes, and it remains unclear which patient subgroups might benefit the most from these therapeutic approaches.

Should we continue to offer patients with these associated nonmodifiable conditions a Norwood operation? This is a difficult question, certainly beyond the scope of this editorial, but one that we still struggle with when confronted with these newborns. Admittedly, other factors weigh on the decision to offer treatment, such as parental desires and individual physician preferences, but our own group has become more conservative in offering surgery when the outcomes are clearly poor. As the results for the Norwood procedure improve, the question still remains: can we modify the nonmodifiable?

\section{References}

1. Mascio CE, Irons ML, Ittenbach RF, Gaynor JW, Fuller SM, Kaplinski M, et al. Thirty years and 1663 consecutive Norwood procedures: has survival plateaued? J Thorac Cardiovasc Surg. 2019;158:220-9.

2. Stasik CN, Goldberg CS, Bove EL, Devaney EJ, Ohye RG. Current outcomes and risk factors for the Norwood procedure. J Thorac Cardiovasc Surg. 2006;131:412-7. 
3. Ashburn DA, McCrindle BW, Tchervenkov CI, Jacobs ML, Lofland GK, Bove EL, et al. Outcomes after the Norwood operation in neonates with critical aortic stenosis or aortic valve atresia. J Thorac Cardiovasc Surg. 2003;125:1070-82.
4. Pasquali SK, Jacobs JP, He X, Hornik CP, Jaquiss RD, Jacobs ML, et al. The complex relationship between center volume and outcome in patients undergoing the Norwood operation. Ann Thorac Surg. 2012;93:1556-62. 